\title{
Cumulative life course and adult socioeconomic status and markers of inflammation in adulthood
}

R A Pollitt, J S Kaufman, K M Rose, A V Diez-Roux, D Zeng and G Heiss

J. Epidemiol. Community Health 2008;62;484-491

doi:10.1136/jech.2006.054106

Updated information and services can be found at:

http://jech.bmj.com/cgi/content/full/62/6/484

These include:

Data supplement

"web only appendices"

http://jech.bmj.com/cgi/content/full/62/6/484/DC1

References This article cites 57 articles, 31 of which can be accessed free at: http:/jjech.bmj.com/cgi/content/full/62/6/484\#BIBL

Rapid responses

You can respond to this article at:

http://jech.bmj.com/cgi/eletter-submit/62/6/484

Email alerting Receive free email alerts when new articles cite this article - sign up in the box at service the top right corner of the article

Notes

To order reprints of this article go to:

http://journals.bmj.com/cgi/reprintform

To subscribe to Journal of Epidemiology and Community Health go to:

http://journals.bmj.com/subscriptions/ 


\title{
Cumulative life course and adult socioeconomic status and markers of inflammation in adulthood
}

\author{
R A Pollitt, ${ }^{1}$ J S Kaufman, ${ }^{1}$ K M Rose, ${ }^{1}$ A V Diez-Roux, ${ }^{2}$ D Zeng, ${ }^{3}$ G Heiss ${ }^{1}$
}

\begin{abstract}
- Additional tables are published online only at http:// jech.bmj.com/content/vol 62/ issue6

${ }^{1}$ Department of Epidemiology, School of Public Health, University of North Carolina at Chapel Hill, NC, USA;

${ }^{2}$ University of Michigan at Ann Arbor School of Public Heath, MI, USA; ${ }^{3}$ Department of Biostatistics, School of Public Health, University of North Carolina at Chapel Hill, NC, USA

Correspondence to: Dr R A Pollitt, 801 Middlefield Rd \#12, Palo Alto, CA 94301, USA; pollitt@stanford.edu
\end{abstract}

Accepted 6 July 2007

\section{ABSTRACT}

Objective: To examine the association between cumulative life course and adult socioeconomic status (SES) and adult levels of inflammatory risk markers (fibrinogen, white blood cell count (WBC), C-reactive protein (CRP), von Willebrand factor (vWF) and an overall inflammatory score).

Design: Retrospective cohort study.

Setting: 12681 white and African-American participants in the Atherosclerosis Risk in Communities (ARIC) study and two ancillary studies.

Methods: Participants provided information on SES and place of residence in childhood and young (30-40 years) and mature (45+) adulthood. Residences were linked to census data for neighbourhood SES information. Multiple imputation (MI) was used for missing data. Linear regression and adjusted geometric means were used to estimate the effects of SES on inflammatory risk marker levels.

Results: Graded, statistically significant associations were observed between greater cumulative life-course exposure to low education and social class and elevated levels of fibrinogen and WBC among white participants. Stronger graded, statistically significant associations were observed between low adult education, social class and neighbourhood SES and elevated inflammatory levels. Associations were weaker and less consistent in AfricanAmericans. Covariate adjustment attenuated results but many associations remained strong.

Conclusions: Our results suggest that cumulative exposure to adverse SES conditions across the life course and low adult SES are associated with an elevated systemic inflammatory burden in adulthood. Chronic systemic inflammation may be one pathway linking low life-course SES and elevated cardiovascular disease risk.

An inverse association of individual ${ }^{1-3}$ and contextual/neighbourhood ${ }^{4}$ socioeconomic status (SES) in adulthood with cardiovascular disease (CVD) has been demonstrated. Low adult SES is associated with poor health behaviours and unfavourable CVD risk factor profiles. ${ }^{35-7}$ Recent research has focused on the influence of life-course SES on $\mathrm{CVD}^{8}{ }^{9}$ : various study designs have been utilised to examine the impact of SES throughout the life course on adult cardiovascular health and several interrelated theories have been posited. ${ }^{10-13}$ Results support a cumulative model of life-course risk, wherein the accumulation of adverse psychosocial and physiological exposures across the life course is associated with increased CVD. ${ }^{9}{ }^{14-18}$

Inquiries into possible mechanisms underlying such associations suggest a sustained, elevated systemic inflammatory burden may mediate social differences in CVD. Chronic and systemic inflammatory upregulation plays a central role in atherosclerosis and its sequelae. ${ }^{19-23}$ Lower adult SES is associated with elevated levels of inflammatory markers such as fibrinogen, white blood cell count (WBC), C-reactive protein (CRP) and von Willebrand factor (vWF). ${ }^{24-26}$ These and other inflammatory markers and cytokines have in turn been linked with CVD. ${ }^{27-34}$ Atherosclerosis begins earlier in life than previously suspected. ${ }^{35}$ SES plausibly affects health behaviours, nutrition, access to health care, exposure to infection and stress throughout life, thereby influencing an individual's systemic inflammatory burden and CVD risk. $^{37}$

Early-life SES has been linked with elevated inflammatory marker levels in other studies ${ }^{36-38}$ and in this cohort. ${ }^{39}$ However, no studies have examined the cumulative influence of exposure to adverse SES across life on adult inflammatory levels. In order to explore cumulative adverse SES exposure and systemic inflammation as a potential pathway by which SES and CVD may be linked, we examined the impact of cumulative life-course and adult SES (measured at both the individual and community levels) on adult levels of fibrinogen, WBC, CRP and vWF and overall inflammatory burden in the Atherosclerosis Risk in Communities (ARIC) study.

\section{METHODS \\ Data}

ARIC is a prospective study of atherosclerosis in 15792 men and women aged 45-64 at baseline (1987-9), sampled from four US communities with an overall $60 \%$ participation rate. ${ }^{40}$ The Life Course Socioeconomic Status, Social Context and Cardiovascular Disease (LC-SES) Study is an ancillary study that retrospectively collected socioeconomic information from childhood (1930-50) and early adulthood (1960-80) on 12681 AfricanAmerican and white ARIC participants in 2001-2. ${ }^{41}$ Individual-level SES and places of residence during childhood and at ages 30, 40 and 50 were collected in ARIC and from annual follow-up telephone interviews.

\section{SES measures}

SES was evaluated in childhood (10 years of age), early adulthood (30-40 years of age) and mature adulthood (45+ years). Individual-level SES was evaluated via social class and education; contextual/neighbourhood-level SES was evaluated using SES indices, described below.

Social class was evaluated utilising a derivation of Wright's schema for categorising social class, an established sociological schema previously examined in epidemiology. ${ }^{42-44}$ Participants were 
Table 1 Assignment of a participant's social class in childhood (via father's education/occupation) and young and mature adulthood (based on Wright's class categorisation) for ARIC participants

\begin{tabular}{llll}
\hline Social class & Higher education* & $\begin{array}{l}\text { Owns business/self- } \\
\text { employed }\end{array}$ & $\begin{array}{l}\text { Supervisory or } \\
\text { managerial job role }\end{array}$ \\
\hline Worker class & No & No & No \\
Middle class & Yes & No & No \\
& No & No & Yes \\
Capitalist/expert manager class & - & Yes & No \\
& Yes & No & Yes \\
\hline
\end{tabular}

*Higher education is some college education or more.

assigned a class at each time point based on education and items evaluating ownership, authority and control facets of their job (table 1). Father's data were used for childhood; principal occupation at 30-40 years of age and current/last occupation were used for young and mature adulthood, respectively. Homemakers were excluded from social class analyses.

Education was evaluated in childhood and adulthood and categorised low/middle/high (table 2). In childhood, father's education was used; in adulthood, participant's education was used.

To evaluate neighbourhood SES, participants' places of residence during childhood and adulthood were linked to US census data (county data for childhood and census tract data for adulthood). ${ }^{45}$ Of 12681 participants, 12373 had US residences in childhood. Of these $12373,98.5 \%$ (12 187) had their childhood residences successfully linked with US county data. Linkage rates in young adulthood were lower: $66 \%$ for 1960 census data, $76 \%$ for 1970 data and $85 \%$ for 1980 data. A neighbourhood SES index was created for each period (table 3) to evaluate contextual/neighbourhood SES. ${ }^{46}$

Cumulative social class, education and contextual/neighbourhood SES measures were created by summing the number of times across the life course one was exposed to the lowest category of SES (table 4)..$^{14} 47$

\section{Physiological covariates and outcomes}

CVD risk factors, fibrinogen, $\mathrm{VWF}$ and WBC were measured at baseline. ${ }^{40}$ Diabetic status was determined by fasting plasma glucose $\geqslant 126 \mathrm{mg} / \mathrm{dl}$, non-fasting plasma glucose $\geqslant 200 \mathrm{mg} / \mathrm{dl}$, self-reported history of physician-diagnosed diabetes or current medication for diabetes. ${ }^{5}{ }^{40}$

Haemostasis variables were analysed in citrated samples, ${ }^{48}$ fibrinogen by the thrombin time titration method and vWF antigen by enzyme-linked immunosorbent assay. ${ }^{49}$ Reliability coefficients were 0.72 for fibrinogen and 0.68 for vWF. ${ }^{50}$ White cell counts were determined using automated cell counters (reliability coefficients $0.96-1.00$ ).

CRP measures were obtained from fasting blood taken from the 5552 participants in the Dental ARIC study during the 1996-8 ARIC Visit (eligibility required having teeth, no medical contraindications to periodontal probing and consent). ${ }^{51}$ CRP was quantified using ELISA assay (range of detection 0.5$50 \mathrm{mg} / \mathrm{l}){ }^{52}$ Intra-plate and inter-plate coefficients of variation ranged from $0-37.3 \%$ and $0-10.6 \%$, respectively.

\section{Statistical methods}

Incomplete earlier-life address, education and census data resulted in high missing data rates for cumulative education $(16.4 \%)$, class $(28.1 \%)$ and neighbourhood SES (36.6\%) measures for the overall cohort. Multiple imputation (MI) was used to reduce bias. ${ }^{53}$ Data were considered to be missing at random (MAR), an assumption that usually holds in self-reported questionnaire data and when erroneous data tend to have only a minor impact on estimates..$^{54}$ Multivariate imputation by chained equations (MICE) was carried out in Stata 8.2 SE utilising 29 demographic covariates and five imputations of 10 iterations. $^{56}$

Inflammatory outcomes were log-transformed. Overall inflammatory burden was assessed using an inflammation score ranging from 0 to 4 (one point was assigned for each of the four inflammatory markers with a level above its race/ethnicityspecific median). This score has been previously utilised and demonstrated a graded, statistically significant association with risk of incident diabetes. ${ }^{57}$ Analyses using CRP or the inflammatory score as outcomes were limited to the 5022 dental ARIC study participants with early-life SES data.

We initially fitted multi-level models with random intercepts for each tract or county to account for residual within-area correlation. However, as they did not significantly improve model fit, we subsequently used linear regression to examine the impact of each SES measure on each inflammatory outcome.

One set of race/ethnicity-specific models (model A) adjusted for age, gender and ARIC centre. A second set (model B) additionally adjusted for high-density lipoprotein cholesterol (HDL-C), low-density lipoprotein cholesterol (LDL-C), body mass index (BMI), hypertension (HTN) and HTN medication, family history of CVD, diabetes status, alcohol intake, smoking status and cigarette-years smoked. For cumulative SES measures, the referent was zero exposures to adverse life-course SES conditions; for adult SES measures, the referent was highest SES.

Geometric mean levels of inflammatory markers were computed for each level of SES by exponentiating parameter estimates. Statistical interaction between SES and potential confounders was assessed using partial $F$ tests. ${ }^{58}$ Tests for linear trend were run using interval SES variables.

\section{RESULTS}

African-American participants had lower scores for adult and cumulative SES measures, higher mean fibrinogen, CRP and

Table 2 Assignment of participants' education group in childhood and adulthood for ARIC participants

\begin{tabular}{llll}
\hline Time point & Low education group & Middle education group & High education group \\
\hline Childhood & 0-8th grade & 9th-12th grade & Some college or more \\
Adulthood & $<$ High school degree & High school degree & Some college or more \\
\hline
\end{tabular}


Table 3 Contextual/neighbourhood SES index for a participant's place of residence at each of the three measured time points (childhood, young adulthood and mature adulthood) for ARIC participants

Step 1 Compute race-specific z-scores of five US census measures:

(1) Median/mean family income

(2) Median/mean value of owner occupied house

(3) Percentage of residents with high school education

(4) Percentage of residents with college education

(5) Percentage of residents in professional/managerial occupations

Step 2 Sum these five z-scores to create a neighbourhood SES index for that time

Step 3. Categorise each index low/middle/high at the 40th and 75th percentiles (based on naturally occurring divisions in the distributions)

vWF levels, and lower mean WBC levels (all $\mathrm{p}<0.001$ ) than white participants (table 5). Patterns were similar across gender groups. Percentages and standard errors are presented for SES measures as these are composite estimates from five multiply imputed datasets. Neighbourhood SES categories were based on race/ethnicity-specific distributions and cannot be directly compared across race/ethnicity groups.

\section{Cumulative life-course SES, white participants}

Among white participants, increasing cumulative life-course exposure to lower SES conditions for all SES measures was associated with elevated levels of each adult inflammatory marker in minimally adjusted models (table 6; vWF results in supplementary table 1). Graded increments in fibrinogen and WBC levels were observed with greater adverse SES exposure ( $p$ for trend $<0.01$ for individual-level SES measures in minimally adjusted models).

Greater cumulative exposure to unfavourable SES was strongly associated with elevated fibrinogen and WBC (table 6). For example, white participants with three versus zero life-course exposures to the worker social class group had geometric mean fibrinogen of $296.3 \mathrm{mg} / \mathrm{dl}$ (95\% CI: 292.4 to 300.2 ), versus $283.9 \mathrm{mg} / \mathrm{dl}$ (95\% CI: 281.8 to 286.1) ( $\mathrm{p}<0.001)$.

Lower categories of all measures were associated with graded elevations in the overall inflammatory score (supplementary table 2). Differences between lowest and highest individuallevel SES categories all attained statistical significance in minimally adjusted models, suggestive of a greater overall inflammatory burden ( $p$ for trend $<0.01$ ).

While CVD risk factor adjustment attenuated all cumulative SES-inflammation associations, increasing adverse life-course exposures remained associated with higher CRP, fibrinogen and vWF (table 6). For fibrinogen, the associations for the mostexposed versus least-exposed groups remained statistically significant in all cumulative SES measures.

\section{Adult SES, white participants}

Lower adult SES was strongly associated with elevated inflammatory levels among white participants (table 6; vWF results in supplementary table 1). Graded elevations in inflammatory markers were observed with decreasing SES for all adult measures ( $p$ for trend $<0.001$ for fibrinogen and WBC in minimally adjusted models). For every adult SES measure, participants in lowest versus highest SES groups had statistically significantly higher levels of all markers; the sole exception was for Worker class adults and CRP. As with cumulative SES, fibrinogen and WBC were strongly associated with adult SES.

Lower categories of all measures were associated with graded elevations in the overall inflammatory score (supplementary
Table 4 Cumulative life-course social class, education and contextual/ neighbourhood SES measures based on a participant's SES in childhood and young and mature adulthood for ARIC participants

\begin{tabular}{ll}
\hline $\begin{array}{l}\text { Cumulative life-course SES } \\
\text { measure }\end{array}$ & Method of creation and range \\
\hline Cumulative social class & $\begin{array}{l}\text { Sum the number of times a participant was in the } \\
\text { worker (lowest) social class category, out of } \\
\text { childhood, young adulthood and mature adulthood. } \\
\text { Range: } 0-3\end{array}$ \\
& $\begin{array}{l}\text { Sum the number of times a participant was in the } \\
\text { low education group, out of participant's and } \\
\text { father's education. Range: } 0-2\end{array}$ \\
Cumulative education & $\begin{array}{l}\text { Sum the number of times a participant lived in a } \\
\text { low SES category neighbourhood, out of } \\
\text { childhood, young adulthood and mature adulthood. } \\
\text { Range: } 0 \text {-3 }\end{array}$
\end{tabular}

*Example: a participant who was in the low neighbourhood SES group in childhood, the middle group in young adulthood and the low group in mature adulthood would have a cumulative neighbourhood SES measure score of 2.

table 2); differences between lowest and highest SES categories were all significant in minimally adjusted models. Relative increments in inflammatory score by SES were similar in size to those observed within levels of cumulative SES.

CVD risk factor adjustment attenuated most associations (table 6). However, low education remained significantly associated with elevated fibrinogen and WBC. Elevated fibrinogen also remained significantly associated with lowest social class and neighbourhood SES. Associations with the inflammatory score were no longer statistically significant after covariate adjustment, but graded associations remained.

\section{Cumulative SES, African-American participants}

Among African-Americans, increasing cumulative exposure to adverse SES was inconsistently associated with elevated inflammatory levels (table 7; vWF results in supplementary table 1). Greater life-course exposure to lower education and social class was associated with elevated fibrinogen and vWF (and CRP for social class) in minimally adjusted models; greater exposure to low-SES neighbourhoods was associated with elevated CRP and fibrinogen. Associations were weaker and less consistent among African-American participants than among white participants. Stepwise, graded elevations in inflammatory marker levels were not consistently observed by cumulative SES category, as they were in white participants. Only slight increments in the overall inflammatory score by greater exposure to adverse SES conditions were observed (supplementary table 2).

CVD risk factor adjustment strongly attenuated the cumulative SES-inflammatory marker associations. Moreover, certain associations were inverted after CVD risk factor adjustment, with greater exposure being associated with lower inflammatory levels.

\section{Adult SES, African-American participants}

Lower adult SES was associated with elevated inflammatory levels among African-Americans (table 7; vWF results in supplementary table 1). Patterns were more consistent than for cumulative SES. Levels of all markers were higher for lowest versus highest category of all SES measures; graded associations were observed for fibrinogen and WBC.

The influence of lower adult SES on inflammation was generally smaller among African-American participants than white participants. For example, the relative increments in CRP, 
Table 5 Means and percentage of socioeconomic measures, inflammatory markers and covariates for white and African-American participants

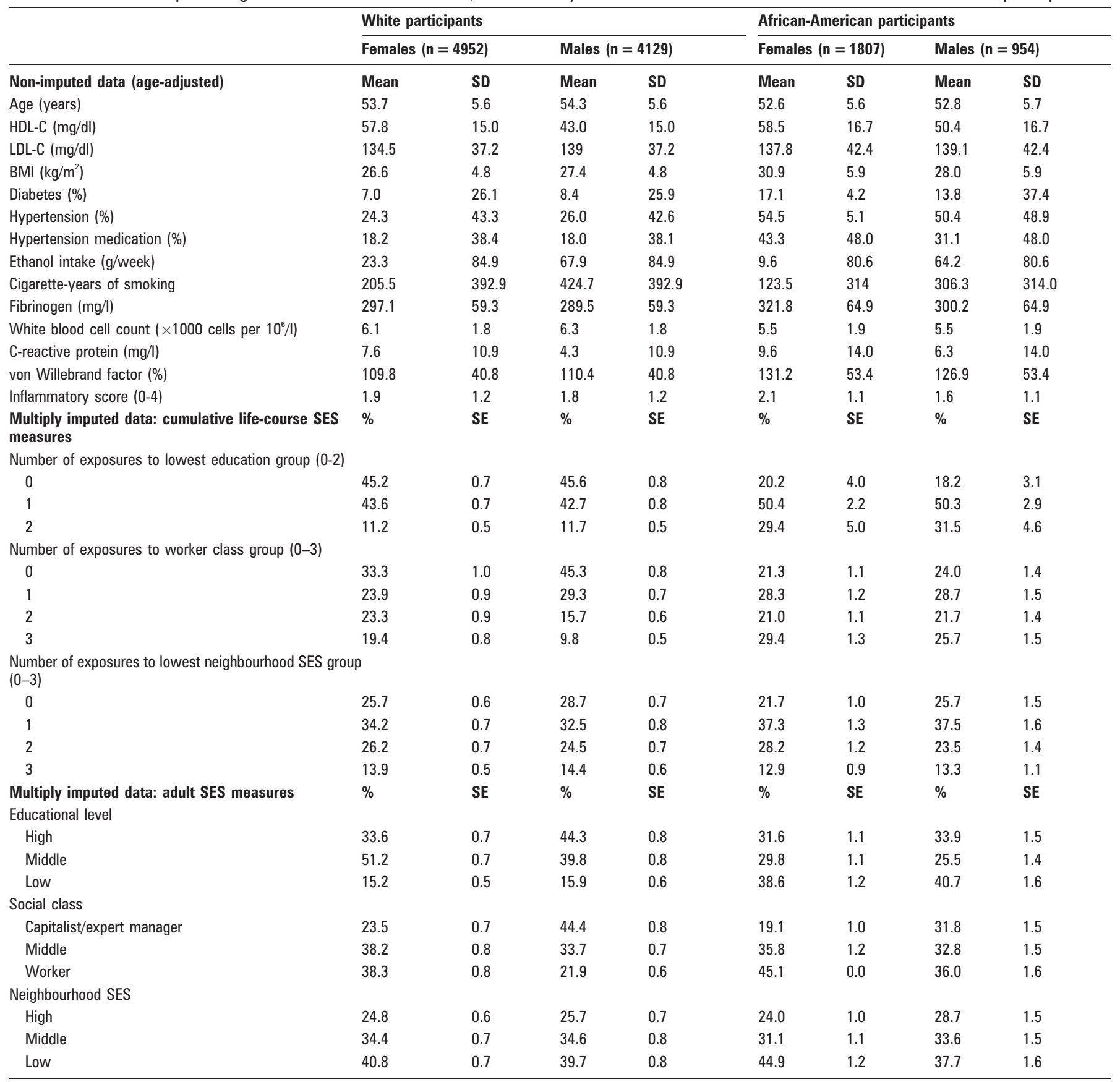

$\mathrm{SD}$, standard deviation; $\mathrm{SE}$, standard error.

fibrinogen, WBC and vWF observed for lowest versus highest education among African-American participants were 18\%, 4\%, $0 \%$ and $7 \%$, respectively, versus $37 \%, 6 \%, 10 \%$ and $5 \%$ for white participants, respectively. Low adult SES was most notably associated with adult fibrinogen, where graded associations were observed for all adult SES measures ( $p$ for trend $<0.05$ ).

Lower adult SES was modestly associated with an elevated overall inflammatory score among African-Americans (supplementary table 2). Associations were smaller than for white participants for individual-level measures, but larger for neighbourhood-level SES ( $p$ for trend $<0.05$ ).

As for cumulative SES, CVD risk factor adjustment substantially attenuated (and in some instances inverted) most associations (table 7).

\section{DISCUSSION}

Cumulative life-course and adulthood SES were markedly, inversely associated with adult inflammatory marker levels among white people. Fibrinogen and WBC were most strongly associated with life-course and adult SES; statistically significant, linear, graded increments in these markers' levels were observed with decreasing SES. CRP and vWF were also inversely associated with SES, although associations did not consistently attain statistical significance. Results among African-Americans were less clear: patterns of association were inconsistent, particularly in covariate-adjusted models. Adult SES was generally more strongly associated with inflammatory levels than life-course SES. Graded, stepwise increments in the overall inflammatory score observed with worse SES (both cumulative 
Table 6 Adjusted geometric means and $95 \% \mathrm{Cl}$ for levels of inflammatory biomarkers by cumulative and adult life-course SES measures and $\mathrm{p}$ value for linear trend among white participants

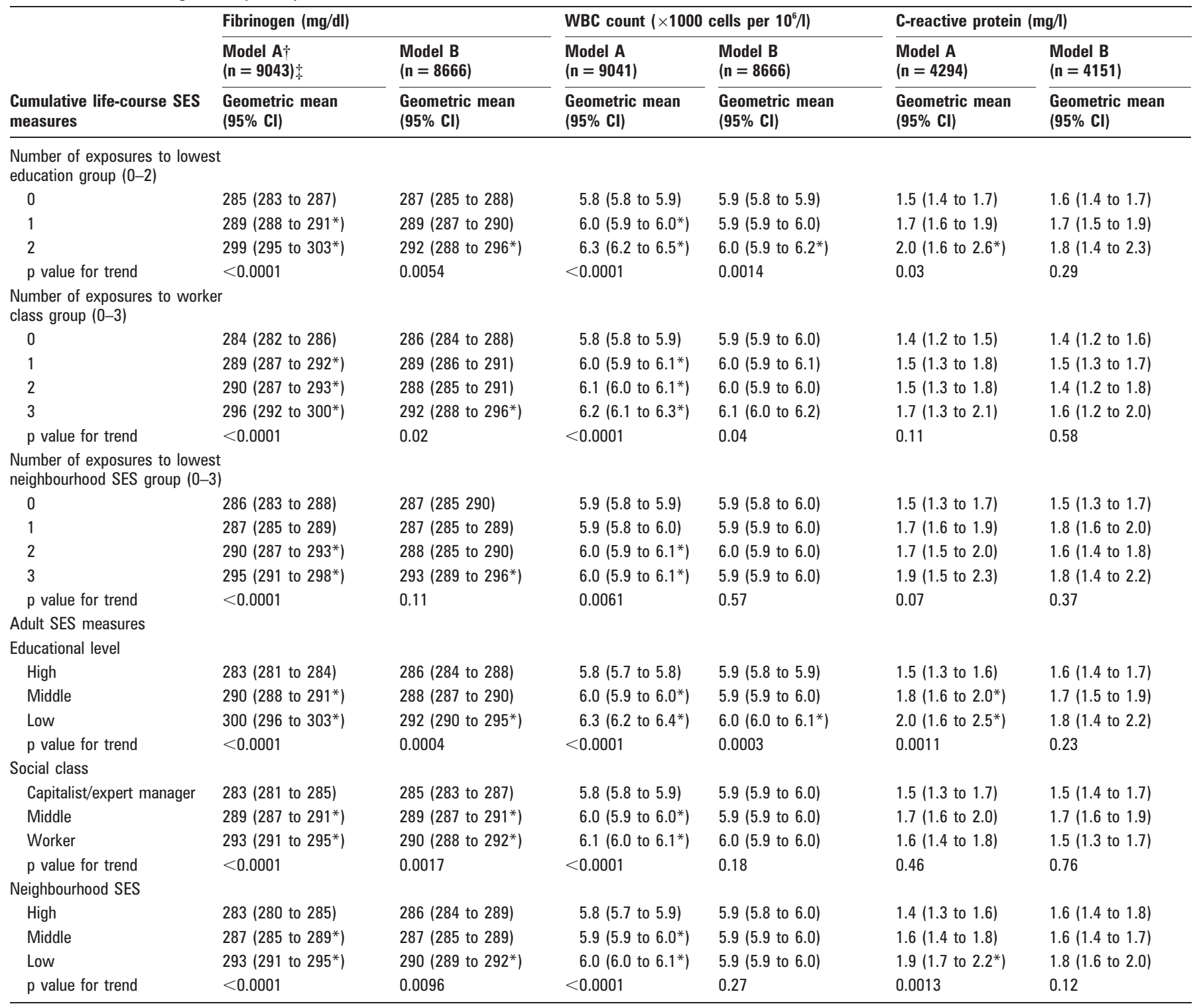

${ }^{*} \mathrm{p}<0.05$ for the SES measure parameter coefficient.

$\dagger$ Model A adjusts for ARIC Center, age and gender. Model B adjusts for model A covariates and HDL cholesterol, LDL cholesterol, body mass index, hypertension and hypertension medication, family history of cardiovascular disease, diabetes status, alcohol intake, smoking status and cigarette-years smoked.

th is number of participants available for analysis of a particular inflammatory response. Specific cell numbers vary by SES measure used.

life-course and adult measures) underline the consistency of the analytical results, particularly among white people.

Weaker, less consistent associations among AfricanAmericans may be due to smaller sample size and power. Also, race/ethnicity-specific SES distributions differed significantly; the range of SES levels among African-American participants was (1) composed of lower SES scores and (2) narrower than the range among white participants. Potentially relevant aspects of SES (for example, healthcare access, experience with racism) were not available. Associations may be patterned differently by race/ethnicity, influenced by differential health selection by race/ethnicity or may point to limitations present in the evaluation of SES among AfricanAmericans in ARIC. ${ }^{6} 4659$

Studies have consistently reported associations between the number of adverse life-course SES exposures and levels of CVD risk factors and events. ${ }^{9}$ Our results support these findings and further suggest that earlier-life exposures to adverse conditions are linked to elevated adult inflammation.

A number of mechanisms may plausibly underlie this link. The fetal origins hypothesis suggests that malnutrition and other physiological insults during critical developmental periods may lead to adult metabolic dysfunction associated with proinflammatory states. ${ }^{60}$ Childhood exposure to adverse SES conditions during sensitive developmental periods may have similar effects. Low SES has been associated with adult health behaviours linked to inflammation, ${ }^{27}$ and life-course SES may be a strong determinant of adult health behaviours given the early development of behaviour patterns. Stress, depression and/or hostility linked to low SES may lead to chronic activation of the hypothalamic-pituitary-adrenocortical axis, increased release of corticosteroids, abnormal platelet function and other conditions. ${ }^{3}$ Finally, low SES conditions/environments plausibly increase exposure to potentially pro-inflammatory or 
Table 7 Adjusted geometric means and $95 \% \mathrm{Cl}$ of inflammatory markers by levels of cumulative life-course and adult SES measures and $\mathrm{p}$ values for linear trend for African-American participants

\begin{tabular}{|c|c|c|c|c|c|c|}
\hline \multirow[b]{3}{*}{ Cumulative life-course SES measures } & \multicolumn{2}{|l|}{ Fibrinogen (mg/dl) } & \multicolumn{2}{|c|}{ WBC count $\left(\times 1000\right.$ cells per $\left.10^{6} / I\right)$} & \multicolumn{2}{|c|}{ C-Reactive protein (mg/l) } \\
\hline & \multirow{2}{*}{$\begin{array}{l}\text { Model } A \dagger \\
(\mathrm{n}=2619) \dagger \\
\text { Geometric mean } \\
(95 \% \mathrm{Cl})\end{array}$} & \multirow{2}{*}{$\begin{array}{l}\begin{array}{l}\text { Model B } \\
(\mathrm{n}=2200)\end{array} \\
\text { Geometric mean } \\
(95 \% \mathrm{Cl})\end{array}$} & \multirow{2}{*}{$\begin{array}{l}\text { Model A } \\
(\mathrm{n}=2639) \\
\text { Geometric mean } \\
\text { (95\% CI) }\end{array}$} & \multirow{2}{*}{$\begin{array}{l}\text { Model B } \\
(\mathrm{n}=2204) \\
\text { Geometric mean } \\
(95 \% \mathrm{Cl})\end{array}$} & \multirow{2}{*}{$\begin{array}{l}\text { Model A } \\
(\mathrm{n}=728) \\
\text { Geometric mean } \\
\text { (95\% CI) }\end{array}$} & \multirow{2}{*}{$\begin{array}{l}\begin{array}{l}\text { Model B } \\
(\mathrm{n}=592)\end{array} \\
\text { Geometric mean } \\
(95 \% \mathrm{Cl})\end{array}$} \\
\hline & & & & & & \\
\hline \multicolumn{7}{|l|}{$\begin{array}{l}\text { Number of exposures to lowest education } \\
\text { group (0-2) }\end{array}$} \\
\hline 0 & $306(300$ to 311$)$ & 308 (302 to 314$)$ & $5.3(5.2$ to 5.5$)$ & $5.3(5.1$ to 5.5$)$ & $2.1(1.5$ to 3.1$)$ & $2.4(1.7$ to 3.5$)$ \\
\hline 2 & 311 (306 to 316) & 308 (303 to 314$)$ & $5.3(5.1$ to 5.4$)$ & $5.2(5.1$ to 5.3$)$ & $2.3(1.6$ to 3.4$)$ & $2.0(1.4$ to 3.1$)$ \\
\hline $\mathrm{p}$ for trend & 0.14 & 0.94 & 0.63 & 0.29 & 0.76 & 0.52 \\
\hline \multicolumn{7}{|l|}{$\begin{array}{l}\text { Number of exposures to worker class } \\
\text { group }(0-3)\end{array}$} \\
\hline 0 & $300(295$ to 306$)$ & 305 (299 to 311$)$ & $5.2(5.1$ to 5.4$)$ & 5.3 (5.2 to 5.5$)$ & 1.9 (1.3 to 2.6$)$ & 1.8 (1.2 to 2.6$)$ \\
\hline 1 & 303 (298 to 308$)$ & 305 (300 to 310$)$ & $5.2(5.1$ to 5.3$)$ & $5.2(5.1$ to 5.4$)$ & $1.8(1.3$ to 2.5$)$ & $1.8(1.2$ to 2.5$)$ \\
\hline 0 & 305 (300 to 310$)$ & 307 (302 to 312 ) & $5.3(5.1$ to 5.4$)$ & $5.3(5.2$ to 5.4$)$ & $1.8(1.3$ to 2.6$)$ & $2.3(1.6$ to 3.4$)$ \\
\hline 1 & 305 (301 to 310$)$ & 306 (302 to 311$)$ & $5.2(5.1$ to 5.3$)$ & $5.2(5.1$ to 5.3$)$ & $2.4(1.7$ to 3.3$)$ & $2.1(1.5$ to 2.8$)$ \\
\hline 2 & 311 (306 to 317) & 308 (302 to 314$)$ & 5.3 (5.1 to 5.4$)$ & $5.2(5.0$ to 5.3$)$ & 2.1 (1.4 to 3.3 ) & 2.0 (1.3 to 3.0$)$ \\
\hline 3 & 312 (305 to 320$)$ & 313 (305 to 321$)$ & 5.3 (5.1 to 5.5$)$ & 5.3 (5.1 to 5.5$)$ & 2.1 (1.3 to 3.5$)$ & 2.0 (1.1 to 3.3$)$ \\
\hline$p$ for trend & 0.029 & 0.39 & 0.79 & 0.66 & 0.65 & 0.57 \\
\hline \multicolumn{7}{|l|}{ Adult SES measures } \\
\hline \multicolumn{7}{|l|}{ Educational level } \\
\hline High & 301 (297 to 305$)$ & 306 (301 to 310 ) & $5.2(5.1$ to 5.3$)$ & $5.3(5.2$ to 5.4$)$ & $1.9(1.5$ to 2.5$)$ & $2.0(1.9$ to 2.0$)$ \\
\hline Middle & $309\left(304\right.$ to $\left.313^{*}\right)$ & 309 (304 to 313$)$ & $5.2(5.1$ to 5.3$)$ & $5.2(5.1$ to 5.3$)$ & $2.3(1.7$ to 3.1$)$ & $2.4(2.3$ to 2.5$)$ \\
\hline Low & 312 (308 to $316^{*}$ ) & 309 (306 to 314$)$ & 5.3 (5.2 to 5.4$)$ & $5.2(5.1$ to 5.3$)$ & 2.3 (1.7 to 3.1$)$ & $2.0(1.9$ to 2.1$)$ \\
\hline $\mathrm{p}$ value for trend & 0.0003 & 0.26 & 0.43 & 0.22 & 0.42 & 0.68 \\
\hline Low & $311\left(308\right.$ to $\left.315^{*}\right)$ & 309 (305 to 313 ) & $5.3(5.2$ to 5.4$)$ & $5.2(5.1$ to 5.3$)$ & $2.4(1.9$ to 3.1$)$ & $2.3(1.7$ to 3.0$)$ \\
\hline$p$ value for trend & 0.021 & 0.91 & 0.28 & 0.76 & 0.13 & 0.089 \\
\hline
\end{tabular}

${ }^{*} \mathrm{p}<0.05$ for the SES measure parameter coefficient.

$\dagger$ Model A adjusts for ARIC Center, age and gender. Model B adjusts for model A covariates and HDL cholesterol, LDL cholesterol, body mass index, hypertension and hypertension medication, family history of cardiovascular disease, diabetes status, alcohol intake, smoking status and cigarette-years smoked.

th is number of participants available for analysis of a particular inflammatory response. Specific cell numbers vary by SES measure used.

infectious agents such as microbial pathogens, ambient air pollutants and adverse work conditions. ${ }^{61}$

Childhood contextual SES was evaluated at the county level while adult contextual SES was evaluated at the census tract level; the impact of early-life contextual SES is therefore probably underestimated. Additionally, the cumulative lifecourse model utilised assumes that adverse SES exposures have the same impact regardless of length or timing of exposure and does not address the potentially differential impact of upward or downward social mobility. ${ }^{9}$ Selective survival of healthier participants, a $60 \%$ baseline participation rate and the availability of CRP only among healthier participants limited the socioeconomic and health diversity of participants and may have biased results towards the null. Errors in remembering early-life SES may also have biased results towards the null. ${ }^{62}$

Strengths of this study include use of SES measures from three life epochs, a separate analysis of adult SES, examination of both individual-level and contextual-level SES and the availability of multiple inflammatory markers. Additionally, the use of MI represents a systematic effort to minimise biases due to missing data.

While the stronger association between adult SES and inflammation is unsurprising, inflammatory levels were closely tied to life-course SES. The graded relations between the number of life-course exposures to low SES and inflammatory levels suggest that the impact of these exposures is cumulative. These findings point to a sustained increase in inflammation as a response to adverse life-course SES, matching the development of chronic vascular disease in young adulthood and progressing throughout life. ${ }^{35}$ Our results suggest a framework linking adverse life-course SES exposures to end-organ pathology in Western industrialised countries. These findings have implications for our understanding of the long-term development and progression of chronic vascular disease and speak to a need for 


\section{What is already known on this subject}

- Low individual-level and neighbourhood-level SES in childhood and adulthood are associated with poor health behaviours and elevated risk of CVD.

- More recently, the accumulation of adverse SES conditions throughout life has been found to be strongly associated with CVD.

- While the pathways underlying these associations remain unclear, recent evidence suggests that one such pathway may be a chronic, systemic inflammatory burden.

\section{What this study adds}

- These results suggest that the accumulation of adverse socioeconomic conditions (at both the individual and neighbourhood level) throughout life is associated with elevated systemic inflammation in adulthood.

- Thus, upregulated inflammatory pathways may be one link between adverse life-course SES exposures and end-organ pathology.

- Future research more thoroughly examining the cumulative health impacts of unfavourable socioeconomic conditions may further our understanding of the long-term development and progression of chronic vascular disease.

\section{Policy implications}

Policies geared towards reducing cardiovascular health inequalities should consider the negative health effects of the accumulation of adverse socioeconomic conditions across the life course.

further examination of the earlier-life development of CVD risk factors and poor health behaviours.

Acknowledgements: The Atherosclerosis Risk in Communities Study is carried out as a collaborative study supported by National Heart, Lung and Blood Institute contracts N01-HC-55015, N01-HC-55016, N01-HC-55018, N01-HC-55019, N01-HC55020, N01-HC-55021 and N01-HC-55022. The authors thank the staff and participants of the ARIC study for their important contributions.

Competing interests: None.

\section{REFERENCES}

1. Kunst AE, Groenhof F, Andersen 0, et al. Occupational class and ischemic heart disease mortality in the United States and 11 European countries. Am J Public Health 1999;89:47-53

2. Kaplan GA, Keil JE. Socioeconomic factors and cardiovascular disease: a review of the literature. Circulation 1993;88:1973-98.

3. Strike PC, Steptoe A. Psychosocial factors in the development of coronary artery disease. Progr Cardiovasc Dis 2004;46:337-47.

4. Armstrong D, Barnett E, Casper M, et al. Community occupational structure, medical and economic resources, and coronary mortality among US blacks and whites, 1980-1988. Ann Epidemiol 1998:8:184-91.

5. Diez Roux AV, Merkin SS, Arnett D, et al. Neighborhood of residence and incidence of coronary heart disease. N Engl J Med 2001;345:99-106.

6. Diez-Roux AV, Nieto FJ, Tyroler HA, et al. Social inequalities and atherosclerosis. The atherosclerosis risk in communities study. Am J Epidemiol 1995:141:960-72.

7. Lynch JW, Kaplan GA, Salonen JT. Why do poor people behave poorly? Variation in adult health behaviours and psychosocial characteristics by stages of the socioeconomic lifecourse. Soc Sci Med 1997:44:809-19.
8. Galobardes B, Lynch JW, Davey Smith G. Childhood socioeconomic circumstances and cause-specific mortality in adulthood: systematic review and interpretation. Epidemiol Rev 2004;26:7-21.

9. Pollitt RA, Rose KM, Kaufman JS. Evaluating the evidence for models of life course socioeconomic factors and cardiovascular outcomes: a systematic review. BMC Public Health 2005;5:7.

10. Hertzman C, Power C, Matthews S, et al. Using an interactive framework of society and lifecourse to explain self-rated health in early adulthood. Soc Sci Med 2001;53:1575-85.

11. Power C, Hertzman C. Social and biological pathways linking early life and adult disease. Br Med Bull 1997:53:210-21.

12. Kuh D, Power C, Blane D, et al. Social pathways between childhood and adult health In: Kuh D, Ben-Shlomo Y, eds. A life course approach to chronic disease epidemiology. Oxford: Oxford University Press, 1997:169-98.

13. Smith GD, Gunnell D, Ben-Shlomo Y. Lifecourse approaches to socio-economic differentials in cause-specific adult mortality. In: Leon DA, Walt G, eds. Poverty, inequality and health: an international perspective. Oxford: Oxford University Press, 2001:88-124.

14. Heslop P, Smith GD, Macleod J, et al. The socioeconomic position of employed women, risk factors and mortality. Soc Sci Med 2001;53:477-85.

15. Smith GD, Hart C, Blane D, et al. Lifetime socioeconomic position and mortality: prospective observational study. BMJ 1997;314:547-52.

16. Lawlor DA, Ebrahim S, Davey Smith G. Socioeconomic position in childhood and adulthood and insulin resistance: cross sectional survey using data from British women's heart and health study. BMJ 2002;325:805

17. Claussen B, Davey Smith G, Thelle D. Impact of childhood and adulthood socioeconomic position on cause specific mortality: the Oslo Mortality Study. J Epidemiol Community Health 2003;57:40-5.

18. Pensola TH, Martikainen P. Cumulative social class and mortality from various causes of adult men. J Epidemiol Community Health 2003:57:745-51.

19. Pearson TA, Mensah GA, Alexander RW, et al. Markers of inflammation and cardiovascular disease: application to clinical and public health practice: a statement for healthcare professionals from the Centers for Disease Control and Prevention and the American Heart Association. Circulation 2003;107:499-511.

20. Ross R. Atherosclerosis--an inflammatory disease. N Engl J Med 1999:340:115-26

21. Huber SA, Sakkinen P, Conze D, et al. Interleukin-6 exacerbates early atherosclerosis in mice. Arterioscler Thromb Vasc Biol 1999:19:2364-7.

22. Hansson GK. Inflammation, atherosclerosis, and coronary artery disease. N Engl J Med 2005;352:1685-95.

23. Libby $\mathbf{P}$, Ridker PM, Maseri A. Inflammation and atherosclerosis. Circulation 2002:105:1135-43.

24. Kumari M, Marmot M, Brunner E. Social determinants of von Willebrand factor: the Whitehall II study. Arterioscler Thromb Vasc Biol 2000:20:1842-7.

25. Owen N, Poulton T, Hay FC, et al. Socioeconomic status, C-reactive protein, immune factors, and responses to acute mental stress. Brain Behav Immun 2003;17:286-95.

26. Panagiotakos DB, Pitsavos C, Manios Y, et al. Socio-economic status in relation to risk factors associated with cardiovascular disease, in healthy individuals from the ATTICA study. Eur J Cardiovasc Prev Rehabil 2005;12:68-74.

27. De Ferranti S, Rifai N. C-reactive protein and cardiovascular disease: a review of risk prediction and interventions. Clin Chim Acta 2002;317:1-15.

28. Danesh J, Collins R, Appleby $\mathrm{P}$, et al. Association of fibrinogen, C-reactive protein albumin, or leukocyte count with coronary heart disease: meta-analyses of prospective studies. JAMA 1998;279:1477-82

29. Folsom AR, Wu KK, Rosamond WD, et al. Prospective study of hemostatic factors and incidence of coronary heart disease: the Atherosclerosis Risk in Communities (ARIC) Study. Circulation 1997:96:1102-8.

30. Jager A, van Hinsbergh WW, Kostense PJ, et al. von Willebrand factor, C-reactive protein, and 5-year mortality in diabetic and nondiabetic subjects: the Hoorn Study. Arterioscler Thromb Vasc Biol 1999;19:3071-8.

31. Tunstall-Pedoe $\mathbf{H}$, Woodward M, Tavendale R, et al. Comparison of the prediction by 27 different factors of coronary heart disease and death in men and women of the Scottish Heart Health Study: cohort study. BMJ 1997:315:722-9.

32. Koenig W, Sund M, Frohlich M, et al. C-Reactive protein, a sensitive marker of inflammation, predicts future risk of coronary heart disease in initially healthy middleaged men: results from the MONICA (Monitoring Trends and Determinants in Cardiovascular Disease) Augsburg Cohort Study, 1984 to 1992. Circulation 1999:99:237-42

33. Ridker PM, Haughie P. Prospective studies of C-reactive protein as a risk factor for cardiovascular disease. J Invest Med 1998;46:391-5.

34. Danesh J, Whincup $P$, Walker $M$, et al. Low grade inflammation and coronary heart disease: prospective study and updated meta-analyses. BMJ 2000;321:199-204.

35. Zieske AW, Malcom GT, Strong JP. Natural history and risk factors of atherosclerosis in children and youth: the PDAY study. Pediatr Pathol Mol Med 2002;21:213-37.

36. Brunner E, Davey Smith G, Marmot M, et al. Childhood social circumstances and psychosocial and behavioural factors as determinants of plasma fibrinogen. Lancet 1996;347:1008-13

37. Wilson TW, Kaplan GA, Kauhanen J, et al. Association between plasma fibrinogen concentration and five socioeconomic indices in the Kuopio Ischemic Heart Disease Risk Factor Study. Am J Epidemiol 1993;137:292-300.

38. Kivimaki M, Lawlor DA, Juonala M, et al. Lifecourse socioeconomic position, C reactive protein, and carotid intima-media thickness in young adults: the Cardiovascular Risk in Young Finns Study. Arterioscler Thromb Vasc Biol 2005:25:2197-202. 
39. Pollitt RA, Kaufman JS, Rose KM, et al. Early-life and adult socioeconomic status and inflammatory risk markers in adulthood. Eur J Epidemiol 2007;22:55-66.

40. ARIC. The Atherosclerosis Risk in Communities (ARIC) Study: design and objectives. Am J Epidemiol 1989:129:687-702.

41. Life Course Socioeconomic Status, Social Context and Cardiovascular Disease (LC-SES) Study. Manual of Procedures 2005.

42. Wright EO. The class analysis of poverty. Int J Health Serv 1995;25:85-100.

43. Wright EO. Class counts: comparative studies in class analysis. Cambridge: Cambridge University Press; Paris Maison des Sciences de I'Homme, 1997.

44. Krieger N, Williams DR, Moss NE. Measuring social class in US public health research: concepts, methodologies, and guidelines. Annu Rev Public Health 1997:18:341-78.

45. Rose KM, Wood JL, Knowles S, et al. Historical measures of social context in life course studies: retrospective linkage of addresses to decennial censuses. Int $J$ Health Geogr 2004;3:27

46. Diez-Roux AV, Nieto FJ, Muntaner C, et al. Neighborhood environments and coronary heart disease: a multilevel analysis. Am J Epidemiol 1997;146:48-63.

47. Smith GD, Hart C. Life-course socioeconomic and behavioral influences on cardiovascular disease mortality: the collaborative study. Am J Public Health 2002;92:1295-8.

48. Papp AC, Hatzakis H, Bracey A, et al. ARIC Hemostasis Study—I. Development of a blood collection and processing system suitable for multicenter hemostatic studies. Thromb Haemost 1989;61:15-9.

49. Clauss A. Gerinnungsphysiologische Schnellmethode zur Bestimmung des Fibrinogens. Acta Haematol 1957;17:237-46.

50. Chambless LE, McMahon R, Wu K, et al. Short-term intraindividual variability in hemostasis factors. The ARIC Study. Atherosclerosis Risk in Communities Intraindividual Variability Study. Ann Epidemiol 1992;2:723-33.
51. Beck JD, Elter JR, Heiss G, et al. Relationship of periodontal disease to carotid artery intima-media wall thickness: the Atherosclerosis Risk in Communities (ARIC) Study. Arterioscler Thromb Vasc Biol 2001;21:1816-22.

52. Slade GD, Ghezzi EM, Heiss G, et al. Relationship between periodontal disease and C-reactive protein among adults in the Atherosclerosis Risk in Communities study. Arch Intern Med 2003;163:1172-9.

53. Horton NJ, Lipsitz SR. Multiple imputation in practice: Comparison of software packages for regression models with missing variables. Am Stat 2001;55:244-54.

54. Schafer JL, Graham JW. Missing data: our view of the state of the art. Psychol Methods 2002; 7:147-77.

55. Collins LM, Schafer JL, Kam CM. A comparison of inclusive and restrictive strategies in modern missing data procedures. Psychol Methods 2001;6:330-51.

56. Royston P. Multiple imputation of missing values. Stata J 2004;4:227-41.

57. Duncan BB, Schmidt MI, Pankow JS, et al. Low-grade systemic inflammation and the development of type 2 diabetes: the Atherosclerosis Risk in Communities Study. Diabetes 2003;52:1799-805.

58. Kleinbaum DG, Kupper LK, Muller KE, et al. Applied regression analysis and other multivariable methods, 3rd ed. Washington: Brooks/Cole Publishing Company, 1998.

59. Borrell LN, Diez Roux AV, Rose K, et al. Neighbourhood characteristics and mortality in the Atherosclerosis Risk in Communities Study. Int J Epidemiol 2004;33:398-407.

60. Godfrey KM, Barker DJ. Fetal programming and adult health. Public Health Nutr 2001;: 4:611-24

61. Zhu J, Nieto FJ, Horne BD, et al. Prospective study of pathogen burden and risk of myocardial infarction or death. Circulation 2001;103:45-51.

62. Berney LR, Blane DB. Collecting retrospective data: accuracy of recall after 50 years judged against historical records. Soc Sci Med 1997;45:1519-25. 